\title{
GUÍA DE BOLSILLO PARA COPYWRITERS
}

\section{Jose Alejandro Polanco Contreras}

\section{RESUMEN}

Cuando se le pide a una persona que redacte un mensaje comercial para un medio masivo, que encuentre ideas llamativas para vender un producto o un servicio y que recuerde que es necesario hacerlo con un lenguaje común, que llegue a todos y sea efectivo, se produce, generalmente, una respuesta en la que se aprecia un poco de incertidumbre. El redactor da vueltas, intenta, regresa y vuelve a probar. Existe siempre el temor frente a una hoja en blanco que debe convertirse, con el paso de las horas, en un buen aviso publicitario.

Sin embargo, "la única forma de escribir en publicidad con éxito es haciéndolo una y otra vez". Sólo el trabajo constante puede llevar a un buen final el aviso que es imposible dejar para mañana. En el artículo se recorren las "profundidades de una selva no explorada: Ios territorios infinitos de la creación". Se detallan los métodos y técnicas utilizados por los redactores exitosos y se organizan en una "guía de bolsillo" para la creación de mensajes en los medios masivos de comunicación.

Los creativos son personas inquietas y buscan constantemente ideas y caminos que lleven al aviso que se requiere. Pero las vueltas que tienen que dar podrían ser menos angustiosas si contaran con un esquema que les permita "aprender lo que no se puede enseñar". Ese es el propósito central del interesante recorrido por las "circunvoluciones" de la redacción publicitaria contenido aquí.

\section{PALABRAS CLAVE}

Copywiter, copy, aviso publicitario, comercial, redactor crea- tivo, viñeta, lema, voz off, encabezados, titulares, subtítulos, flash, promos, infomerciales,

\section{ABSTRACT}

When a person is asked to draft a commercial message for mass media, find flashy ideas to sell a product or service, and be reminded that it is necessary to do this in simple language which reaches everyone and is effective, as a general rule, a response is produced where a bit of uncertainty is evidenced. The writer spins around, tries, comes back and tries again. Fear always exists in the face of a blank page which must be turned over the course of hours into a good advertisement,. However, "the only way to write successfully in advertising is by doing it over and over again". Only constant work can take an ad, which is impossible to leave for tomorrow, to a happy ending. The "depths of an unexplored jungle: the infinite territories of creation" are traversed in the article. The methods and techniques used by successful copywriters are expounded and organized in a "pocket guide" for the creation of messages in mass means of communication.

Creative people are restless and constantly seek ideas and routes which lead to the ad required. The efforts they have to make, however, could be less anxiety-ridden if they had a scheme allowing them to "learn what cannot be taught". This is the main goal of the interesting tour through the "gyrations" of copywriting presented here. 
"La redacción no tienen nada de divino y a la vez lo tiene todo.

Introducción confusa para quienes quieren seguir reglas."

\section{INTRODUCCIÓN}

Enfrentarse a una hoja en blanco hace que de inmediato tengamos deseos de sacar
Es muy posible que se nos vaya nuestra existencia y no podamos llegar a redactar un texto tan bien como debería ser, pero porlo menos sabemos que cada borradorque avanzamoses un paso más hacia una excelencia que rara vez se alcanza. una figurita, la del santo que más audiencia tenga, y nos encomendemos a él en fervientes oraciones. Cuando se le piden ideas a las personas y los textos que las pongan en un lenguaje común, las caras de muchos inmediatamente ponen una mueca de dolor. La hoja en blanco los castiga cada vez que la miran y se convierte en un perpetuo interrogante. Así debe ser el infierno de los que nunca tuvieron ideas y se dedicaron a vivir de los logros ajenos y a cosechar glorias con las "estupideces de otros". Pero estos momentos angustiosos, de incubación forzada que llegan a provocar incluso dolores de cabeza (de esto dan fe algunos estudiantes con testimonios de los males que les ha ocasionado redactar una campaña) nos sirven para dejar en claro una de las verdades más contundentes que tiene la redacción publicitaria: la única forma de escribir en publicidad con éxito es haciéndolo una

\section{RESEÑA AUTOR:}

José Alejandro Polanco Contreras, consultor en mercadeo y pensamiento creativo, especialista en Mercadeo Estratégico del Colegio de Estudios Superiores en Administración CESA. Estudios en Dirección de Cine en la Universidad de California UCLA y Producción en el Hollywood Film Institute HFI. Catedrático vinculado con las universidades Jorge Tadeo Lozano, Politécnico Grancolombiano, Universidad Central y CESA; director creativo de varias agencias de publicidad nacionales e internacionales; director de mercadeo y Jefe de Programación Internacional de programadoras y canales de televisión, socio fundador del grupo de comunicación integral Comunico Anima Films. y otra vez. La inspiración divina no existe, hasta ahora ningún texto triunfador de una pieza se le debe a la "Virgencita", el trabajo arduo es la única alternativa. Sí, un 99\% de transpiración como rezan por ahí.

Se podría esperar entonces de un manual para redacción publicitaria, recetas y pócimas mágicas con las que se llegue a la fama y precisamente en este punto es en donde la redacción es una tarea divina. ¿Pero cómo así? ¿No habíamos quedado en que esto no tiene nada de divino?

Tal es la maravillosa contradicción de la escritura, frente a la redacción publicitaria y, en general, sobre cualquier tarea artística; si fuera tan fácil como seguir un par de reglas, todo el mundo lo podría hacer. Esta es la mala noticia. Este manual no lo puede hacer un mejor escritor de anuncios publicitarios y ni siquiera se puede pensar en él como una forma para aprenderlos a hacer. Suena desconcertante, pero hay que ser honestos. La única forma de ser un buen escritor publicitario, es dedicarse una vida a serlo y posiblemente al final de un par de décadas podríamos decir que hemos empezado a escribir un poco mejor nuestros anuncios publicitarios. Lo mejor es ser humildes y vivir con el peso y la culpa que conlleva aceptar un rótulo a crédito de largo plazo, con la inseguridad de que no lo podamos pagar en vida. Es muy posible que se nos vaya nuestra existencia y no podamos llegar a redactar un texto tan bien como debería ser, pero por lo menos sabemos que cada borrador que avanzamos es un paso más hacia una excelencia que rara vez se alcanza.

Lo que se puede encontrar en estas sencillas páginas son algunas huellas seguidas por cientos de redactores publicitarios que han encontrado en estos caminos la forma 
de ingresar a las profundidades de una selva no explorada: los territorios infinitos de la creación. Aquí pueden encontrar un mapa con los caminos más utilizados, con una que otra advertencia sobre rutas que no hacen sino dar círculos y lo pueden llevar a perder tiempo. Esta es una guía de bolsillo para redactar avisos en medios impresos, televisión y radio. Una guía que se puede llevar a todas partes, porque en todas partes nos asaltan las ideas, porque los "creativos" no se quedan quietos, salen a caminar ideas y no les gusta cargar nada en la mano, porque en ocasiones no necesitan de escritorios más grandes que un pedazo de servilleta y los desafíos más grandes.

Pero ante todo es una humilde invitación a que se pierdan en los caminos de la creación para publicidad. Una invitación para aprender lo que no se puede enseñar.

\section{ALGUNAS RECOMENDACIONES ANTES DE ESCRIBIR UN TEXTO PUBLICITARIO}

Lo primero que siempre se ha de tener en cuenta es que se posee un argumento de venta claro. Basado en un solo beneficio y que sea coherente con los lineamientos descritos en las estrategias trazadas al respecto. Recuerde que el público objetivo de su anuncio, en la gran mayoría de las ocasiones desconoce gran parte del producto; es posible que lo reconozca de vista y que jamás lo haya comprado, por eso es importante asegurarse de escribir de forma clara y sobretodo no asumir que algo se va a sacar por deducción. La gente evita la publicidad y con mayor razón las deducciones que tengan que hacer de esta.

Escriba de manera que la gente pueda seguir la información paso a paso, estimulando la imaginación del lector.
Si bien es cierto que se puede decir todo sobre un producto en un solo anuncio, lo recomendable es remitirse sólo a los objetivos publicitarios. Evite llenar páginas porque le han quedado campos vacíos. No haga ni deje hacer a cualquier persona apreciaciones contables sobre los centímetros cuadrados que ha comprado, su costo y cómo aprovecharlos al máximo. Estas apreciaciones administrativas y financieras y sus teorías sobre el máximo provecho de las inversiones nos son aplicables en publicidad.

Muchos directores de arte insisten constantemente en el hecho de que: "En diseño menos es más", y tienen mucha razón. No le tenga temor al vacío y no lo llene con texto inoficioso. Mantenga siempre presente que un buen $\operatorname{cop} y$, ante todo es una buena estrategia. Eso sí cargada de buena seducción.

\section{LOS ENCABEZADOS SON EL PLOMO CALLENTE DE LOS MEDIOS IMPRESOS.APUNTE BIEN Y DISPARE}

Un buen encabezado capta la atención, despierta el interés de los lectores, los conduce hacia el cuerpo del anuncio y presenta el mensaje de venta. Es en definitiva el gancho de entrada para atrapar prospectos. Es la punta de lanza y es tarea de los redactores dirigirla exactamente al gusto de quien está leyendo el anuncio.

Una forma común de atraer la atención consiste en ocupar la mitad de la parte superior con un encabezado escrito en letras grandes. Esta técnica puede resultar tan atractiva como una fotografía o una ilustración de gran efecto visual.

Otra meta del encabezado es despertar el interés de la audiencia y hacerlo rápidamente dándole un buen motivo para que
Una forma común de atraer la atención consiste en ocupar la mitad de la parte superior con un encabezado escrito en letras grandes. Esta técnica puede resultar tan atractiva como una fotografía o una ilustración de gran efecto visual. 
lea el resto del anuncio. Si carece de relevancia, la gente se concentra en otro tema, sin haberse fijado en el mensaje del anuncio.

El encabezado es lo más importante que el anunciante dice al público. Explica la ilustración o amplía su significado; inmediatamente después establece la posición del anunciante en su mente, sin importarle si el receptor decide seguir leyendo. En teoría, los encabezados deben presentar la idea completa de la venta. La investigación revela que, en promedio, de tres a cinco personas más leen el encabezado que las que leen el texto. Por tanto, si el anuncio no logra la venta en él, el anunciante perderá dinero y este es un riesgo que no podemos correr.

Los encabezados contribuyen a desencadenar la respuesta de reconocimiento, la cual viene a reforzar el posicionamiento y la preferencia de la marca.

Se piensa que los encabezados cortos de una línea son los más eficaces, pero una segunda línea es aceptable. En opinión de muchos expertos, los encabezados con diez palabras o más logran mayor cantidad de lectores. David Ogilvy sostiene que el mejor encabezado que escribió contenía 18 palabras, y se convirtió en un clásico: "A 60 millas por hora, el ruido más fuerte de un nuevo Rolls-Royce proviene del reloj eléctrico" ("At 60 miles an hour, the loudest noice in the new Rolls-Royce comes from the electric clock").

Recuerde que: no hay textos largos y cortos. Sólo textos buenos y malos.

\section{TIPOS DE TITULARES.}

Los hay de diferentes calibres.

Escoja el que más le convenga.

\section{El IITULAR DIRECTO}

La voz imperativa es de mandato directo. La teoría psicológica aprovecha la influencia histórica del pensamiento autoritario del servilismo feudal y explica que la gente tiende a hacer lo que se Ie ordena. La eficacia de ser directo cada vez se pone en duda, pues las expresiones se han desgastado tanto, que se han vuelto "publicismos". El tiempo les ha hecho mella y son tan comunes que fácilmente pasan desapercibidas.

Expresiones como: "Venga hoy mismo", "Envíe el cupón ahora", "Llame ya", hacen parte de un inmenso paisaje de anuncios que no se diferencian los unos de los otros y conforman la población más grande de los periódicos.

Los titulares poco amables por su brevedad pueden llamar la atención. Pero hay que tener en cuenta que redactamos para seres humanos y entre más delicado sea el lenguaje, logra mejores resultados. Sea muy directo cuando tiene un beneficio que nadie puede ofrecer, cuando su promesa rompe todos los convencionalismos, cuando una promoción tiene un descuento que es único en su clase. De lo contrario, evite este tipo de titulares. Son poco persuasivos y siendo más prácticos, a nadie le gusta que le den órdenes.

\section{LOS IITULARES QUUE HACEN REFERENCIA AL NOMBRE}

Comercial de fábrica del producto o servicio:

Por lo general, son productos o servicios que gozan de amplio posicionamiento entre los consumidores; nombres conocidos y familiares de productos, servicios o distribuidores, incluso, de los nombres de casas detallistas o de las marcas de fábrica. Por ejemplo: "Suramericana: unos tigres 
en protección", o "Siempre Coca- Cola", son ideales cuando la mención de la marca puede evocar una sensación de confianza.

\section{LOS TITULARES DE PROMOCIÓN}

Se trata de un recurso que no todas las compañías emplean, pues algunas estiman que manejar promociones continuas pone al producto en desventaja ante la competencia:

"Los precios más bajos siempre están en almacenes el Bombazo". "Heladino de Crem Helado siempre tiene un regalo monstruoso para ti", pueden considerarse de la familia de los titulares directos. Funcionan siempre y cuando su redacción involucre un beneficio.

\section{LOS IITULARES INTERROGATIVOS}

Tienen amplia aplicación para despertar la curiosidad con preguntas directas, lógicas y sencillas. Ocasionalmente, estos recurren al doble sentido y a la alusión sexual por medio del humor:

“¿No le gustaría hacerlo más a menudo en su cocina?"

Es obligatorio hacer una advertencia: la combinación de sexo y humor en publicidad requiere de gran cuidado y talento. Si quiere poner en su anuncio un chiste flojo o un comentario de mal gusto, tenga mucho cuidado porque puede caer en un error de estilo y esos son imperdonables.

Otra forma de utilizar los titulares interrogativos es haciendo preguntas sobre vivencias de los consumidores, sobre problemas que no se han podido solucionar. No haga preguntas cerradas, de sí o no. Es posible que alguien conteste con una negativa y pase la página:

“iLe interesa un seguro de vida?” -No gracias.
LOS IItULARESCOMBINADOS

Se orientan en apoyo de la imagen que se ilustra; cobran sentido cuando dejan al consumidor la tarea de hacer mentalmente la combinación. En ocasiones, la imagen dramatiza un entorno y el titular asume la función de enlace para establecer la necesidad razonada en la mente del consumidor.

Por ejemplo: Los anuncios de Niké en los que se muestran fotografías de imágenes reconocidas del mundo del deporte, como Michael Jordan y junto a ellos aparece su lema bandera "Just do it" ("Solamente hazlo"), como un reconocimiento a la voluntad y a sus logros. Este, sin lugar a dudas, es el matrimonio más común en publicidad y su éxito es parte del trabajo en equipo de la dupla gráfico - copy. La clave es que ambos piensen en una sola estrategia, eso sí, cada uno trabajando en el lenguaje en que se sabe comunicar. Aunque en muchas ocasiones los gráficos escriben excelentes textos y los copys encuentran imágenes inmejorables.

\section{LOS IITULARES DE CANALIZACIÓN O PERSUASIÓN SELECTIVA}

Están dirigidos a un segmento determinado del público y se caracterizan por la orientación de su llamamiento enfocado a un sector determinado de hombres, mujeres o niños. Son titulares con alta especificidad, por ejemplo: “Con Curity es muy fácil ser bebé... y también mamá! “, son ideales para segmentar y para hacer llamados a quienes nos interesan.

\section{LOS IITULARESNOTICLA}

Son, en esencia, la entrada a una información o mensaje con el que se pretende dar a conocer algo nuevo. Resultan ideales cuando se presentan retoques al producto
Lacombinación de sexo y humor en publicidad requiere de gran cuidado y talento. Si quiere poner en su anuncio un chiste flojo o un comentario de mal gusto, tenga mucho cuidado porque puedecaeren un error de estilo y esos son imperdonables. 
Utilice palabras sencillas, comunes, familiares. $\mathrm{El}$ reconocimiento y la comprensión mejoran si las palabras son fáciles de entender y reconocer.

Escriba como la gente habla. o se logran reconocimientos que van a crear una mejor imagen de marca. Las promociones se pueden incluir en este segmento. Lo que distingue al titular publicitario de cualquiera otra información es su propósito esencialmente persuasivo.

Ambas formas de comunicación se presentan en un esquema de alud cotidiano de información recibido por el consumidor.

Sin embargo, la noticia se da en un contexto de tipo referencial, en tanto que el mensaje publicitario gira en un eje connotativo y tiene carácter comercial; se cifra en la perspectiva psicológica de satisfacer o crear una necesidad en el consumidor. A diferencia del de noticia, el titular publicitario no se limita a un número de letras y espacios, de manera que el redactor tiene mayor libertad para utilizar el número de líneas que el titular requiera.

\section{TIPSDE beLlezA para SUS ENCABEZADOS}

- El titular debe cumplir, en parte, la primera y la segunda etapa del proceso de venta $y$, en cierta medida, depende de él provocar en el lector, oyente o televidente, la inquietud de conocer más. Su construcción, adecuada a cada caso, representa una parte clave en la redacción de textos.

- Aunque muchos titulares concuerdan con la imagen que se muestra en los anuncios, ello no significa que su empleo sea regla general; es un factor importante, pero no el único. Conviene recordar que muchos nombres de fábrica han cobrado tal posición; que una sola imagen y el nombre son más que suficiente.

- Haga que el encabezado sea el princi- pal componente de convencimiento del anuncio. Cinco veces más personas leen el encabezado que el cuerpo del texto de un anuncio.

- Diríjase al interés del lector con una promesa básica de beneficios que la marca ofrece. No se olvide de las estrategias, ellas son la brújula para navegar en la redacción publicitaria.

- Incluya toda la información posible en el encabezado sin hacerlo largo o pesado.

- En lo posible incluya el nombre de la marca en el encabezado.

- Invite al lector para que lea el cuerpo del texto.

- Seduzca al lector para que examine el material visual del anuncio. Un encabezado fascinante puede llevar al lector a examinar cuidadosamente los aspectos visuales del anuncio.

- Nunca cambie la fuente tipográfica de un encabezado. El cambio de la forma y estilo del material impreso aumenta la complejidad de la impresión visual y afecta negativamente a los lectores.

- Nunca use un encabezado cuya repercusión de convencimiento descienda en la lectura del cuerpo del texto o lo que es peor, que no tenga relación alguna, o fácil de percibir con el cuerpo de texto.

- Utilice palabras sencillas, comunes, familiares. El reconocimiento y la comprensión mejoran si las palabras son fáciles de entender y reconocer. Escriba como la gente habla.

Estas pequeñas sugerencias son solamente un punto de partida. Nadie tiene la verdad definitiva sobre la redacción de encabezados. Lo único cierto es que en últimas, un buen encabezado es aquel que hace 
una grandiosa introducción a los argumentos de venta del producto.

\section{SI ERES BUENO CON LA DERECHA, QUUE TAL SI TAMBIÉN PEGAS CON LA IZOUIIERDA.}

EL SUBTITULO YSU AYUDA AL IITULAR

El subtitulo consiste en unas cuantas palabras o una oración corta que con frecuencia aparece arriba o abajo del encabezado. Cuando aparece arriba recibe el nombre de "antetítulo". Incluye información importante de la marca que no se halla en el encabezado. El subtitulo sirve básicamente al mismo propósito que el encabezado: comunicar con rapidez puntos clave de venta o información sobre la marca. El subtítulo por lo general tiene talla de tipografía mayor que el cuerpo del texto, pero menor que el encabezado. En muchos casos, el subtitulo es más largo que el encabezado y se utiliza para comunicar puntos de venta más complejos. El subtítulo debe reforzar al encabezado y, de nuevo, seducir al lector para que lea el cuerpo del texto. Lo más importante es que le da más poder al encabezado sirviendo como puente entre la introducción y el cuerpo del texto. Los subtítulos logran estimular una lectura más completa de todo el anuncio. Si el encabezado atrae la atención, el subtitulo estimula el movimiento a través del espacio físico del anuncio, incluidos los aspectos visuales. Una buena regla empírica dice que conforme más largo sea el cuerpo del texto, más apropiado es el uso de subtítulos. Sin embargo, la mayor parte de los redactores tratan de mantener el uso de subtítulos al mínimo posible. Creen que si los aspectos visuales y el encabezado de un anuncio no logran comunicar el beneficio del producto con rapidez y claridad, el anuncio no es muy bueno. Pero son creencias. Recuerde que en publicidad no hay reglas.

\section{EL CUERPO DEL TEXTO SE REDACTA COMO SI FUERA UN HOT BODY.}

EL CUERPO DE TEXTO

El cuerpo del texto es el componente escrito de un anuncio y expone el mensaje completo de una marca. Un cuerpo de texto eficaz está escrito de tal manera que se aprovechan y refuerzan el encabezado y el subtitulo; es compatible y gana fuerza con los aspectos visuales, y resulta interesante para el lector. Que el texto sea interesante o no, es una función de la precisión con que el redactor y otras personas que toman decisiones evaluan los diversos componentes de desarrollo del mensaje. Por más elaborado que sea un texto, probablemente resulte ineficaz si "está fuera de la estrategia".

Existen varias técnicas habituales para preparar el texto. El enfoque de texto de línea directa explica en términos concisos la razón por la cual un lector se beneficiará con el uso de la marca. Esta técnica se utiliza muchas veces en forma conjunta con una estrategia de mensaje dirigida a los beneficios. El texto que utiliza el diálogo entrega los puntos de venta de un mensaje al público mediante un personaje o personajes en el anuncio.

El testimonio recurre al diálogo como si el vocero sostuviera mediante el texto una conversación unilateral con el lector. El diálogo también puede mostrar en el anuncio a dos personas que conversan, técnica que se utiliza a menudo en los mensajes del tipo imagen de la vida.

La narración es un método de preparación del texto que simplemente expone una serie de declaraciones acerca de la marca. 
Puede mostrar o no una persona que entrega el texto. Es difícil hacer que esta técnica cobre vida para el lector, de manera que siempre está presente la amenaza de escribir un anuncio soso si se utiliza esta técnica. En muchos sentidos, el texto de respuesta directa es la menos compleja de las técnicas de texto. Al escribirlo, el redactor trata de
Hablaral receptoro crearle un estado de ánimo condescendiente da como cortocircuito en la comunicación. El texto que causabuena impresión en el lector, porque Ie sugiere que se escribió específicamente para él, reduce la oportunidad dequese considere el anuncio una comunicación masiva generalizada. resultado un destacar la urgencia de actuar de inmediato. Por lo tanto, el campo de posibilidades para el texto de respuesta directa está muy restringido. Además, muchos anuncios de respuesta directa confían en instrumentos de promoción de ventas (cupones, concursos y descuentos) como medios de estimular la acción. Fijar fechas límite al lector también es un enfoque común en la publicidad de respuesta directa.

Estas técnicas de redacción establecen un conjunto general de estilos que pueden usarse como formato para el cuerpo del texto. De nuevo, esté consciente de que es posible emplear cualquier objetivo del mensaje con cualquier técnica específica de texto. Existe una gran cantidad de combinaciones compatibles.

\section{HERRAMIENTAS MÁS COMUNES PARA REDACTAR UN BUEN TEXTO}

- Use el tiempo presente siempre que sea posible.

- Declarar afirmaciones de la marca en tiempo pasado o futuro reduce su credibilidad y oportunidad. Hablar al público objetivo acerca de cosas que sucedieron o sucederán da la impresión de promesas huecas. Redactar en tiempo presente hace que los lectores sientan que la marca está en movimiento, que se encuentra trabajando por ellos.
- Use nombres y verbos en singular.

- Una sola persona a la vez suele leer el anuncio, y esa persona evalúa sólo una marca. El uso de sustantivos y verbos en plural reduce la concentración sobre el atributo del artículo o marca que se destaca, y hace que el anuncio resulte menos personal.

- Use palabras y f rases conocidas.

- Un desafió formidable para un redactor consiste en apoyarse en palabras y frases conocidas para comunicarse en forma interesante y singular. Las palabras conocidas quizá parezcan comunes y trilladas. El reto radica en estilizar de manera creativa lo que es conocido y cómodo para el lector, con objeto de que surjan el interés y la emoción. No confunda creatividad con hablar en términos rebuscados que nadie entiende.

- Varié la longitud de oraciones y párrafos.

- El uso de oraciones y párrafos de distintas longitudes no solo sirve para incrementar el interés, sino que también ofrece una impresión visual capaz de hacer que un anuncio resulte más atractivo y legible.

- Haga participar al lector.

- Hablar al receptor o crearle un estado de ánimo condescendiente da como resultado un cortocircuito en la comunicación. El texto que causa buena impresión en el lector, porque Ie sugiere que se escribió específicamente para él, reduce la oportunidad de que se considere el anuncio una comunicación masiva generalizada. Redacte sus textos publicitarios como si le hablara a un amigo.

- Apoye lo que parezca increíble. 
- Una marca tal vez tenga muchas características o funciones que el lector encontraría difíciles de creer. En los casos en que estas afirmaciones sean determinantes para el posicionamiento de la marca en el mercado y para brindar valores al consumidor, hace falta documentar (con resultados de pruebas o testimonios) que la marca en realidad hace lo que afirman las declaraciones. Sin un respaldo correcto de las afirmaciones, la marca perderá credibilidad y, por lo tanto, la relevancia para el consumidor. No prometa nada que no pueda cumplir o demostrar si es el caso.

- Evite las expresiones trilladas y los superlativos.

- A diferencia de lo que se piensa las expresiones trilladas rara vez llaman la atención y captan la atención. Usualmente el consumidor que se encuentre anuncios de este tipo piensa que las marcas que promociona son anticuadas y de origen poco dudoso. Todo lo que se tiende a exagerar es porque su defecto ha de tener.

\section{SON COMO TORO AL LLANERO SOLITARIO}

LAILUSTRACIÓN YSU RELACIÓN CON EL TEXTO

Cuando se hallan ante un anuncio impreso, la mayoría de las personas ven primero la fotografía o imagen, luego leen el encabezado y finalmente el cuerpo del texto, en ese orden.

Como gran parte del éxito del anuncio depende de la ilustración, esta ha de ser diseñada teniendo en cuenta varias metas:

- Captar la atención del lector.

- Despertar el interés del lector con el encabezado.

- Explicar las afirmaciones hechas en el texto publicitario.
- Identificar el tema del anuncio.

- Mostrar el producto en el momento de usarlo.

- Seleccionar a los lectores deteniendo a los que son verdaderos receptores.

- Ayudar a convencer al lector de la verdad de lo que se afirma en el texto.

- Poner de relieve las características especiales del producto.

- Causar una impresión favorable del producto o del patrocinador.

- Ofrecer continuidad a la campaña aplicando una técnica visual unitaria en cada anuncio.

\section{PALABRAS QUE TIENEN ENERGÍA ATÓMICA.}

EL LEMA

El lema se caracteriza por una frase corta y rotunda. Tiene una función polisémica que asume el papel de síntesis, de elogio, como reiteración, complemento o remate en favor de la imagen institucional. Guarda una estrecha relación con el logotipo, ya que, ocasionalmente, lo sustituye en los anuncios orales destinados a los medios audiovisuales. Por su naturaleza grafica verbal, su clasificación semántica y semiótica está centrada en la máxima simplicidad de su simbolización.

Es frecuente el uso del lema acompañado del logo en el cierre de gran número de anuncios. Suele orientarse de manera ágil y fácil de recordar, tomando en cuenta que la gente reacciona de manera positiva ante las imágenes verbales; pero, también, tiende a asociarse al nombre de la empresa. Todo lema debe responder a las condiciones de levedad, rapidez, exactitud, visibilidad, multiplicidad y consistencia. En la publicidad hay una lista infinita de ejemplos; en cada marca se puede encontrar uno; 
incluso hay algunos que se han convertido en parte de la identidad del país como es "Colombiana la nuestra" y otros en alguna oportunidad han conseguido tener un sentido de omnipresencia como si se trataran de una deidad, "Siempre Coca-Cola", es un ejemplo de esto.

Joaquín

Lorente

dice: " $\mathrm{La}$

televisión es la penicilina de la publicidad", $y$ es una verdad contundente.

Esta frase, en últimas, resume lo que significa la televisión en publicidady esto es poder.

\section{LA ARTILLERÍA PESADA DE LA PUBLICIDAD. LATELEVISIÓN}

Joaquín Lorente dice: "La televisión es la penicilina de la publicidad", y es una verdad contundente. Esta frase, en últimas, resume lo que significa la televisión en publicidad y esto es poder. Bueno, poder a un costo alto, pero poder al fin y al cabo, lo que es algo muy apetecido por los clientes en el momento de compra de espacios publicitarios. Pero así como la televisión se presenta como una pócima mágica para obtener excelentes resultados, como todo poder hay que manejarlo con mucho cuidado y como es obvio también, tiene una serie de villanos que lo acechan permanentemente. Lo primero que hay que tener en cuenta en cuanto a la televisión como herramienta, es que esta nunca se debe hacer como si se tratara de un acto de beneficencia en donde los presupuestos se han sacado a regañadientes y el pago por el talento de los realizadores parece más un sacrificio que una inversión. A todo el mundo le parece fácil tomar una cámara y hacer un spot publicitario. Todo el mundo piensa que es tan fácil como grabar un cumpleaños; muchos clientes cuando están en los rodajes de comerciales por primera vez exclaman asombrados: "Yo no pensé que esto fuera tan difícil" y tienen razón, no es que sea difícil, porque como en todos los campos hay gente que lo hace un juego de niños; tienen razón porque hacer televisión es algo de inmenso cuidado. Hacer publicidad aquí es el cuidado de los detalles y la lucha eterna contra la "ley de Murphy". Si se destinan las sobras para hacer televisión, va a tener un mensaje de la misma manera. Hecho con sobras y lo que es más importante: la marca se verá sostenida con sobrantes y retazos, y siendo honestos ¿qué ama de casa dejaría entrar una marca vestida con harapos a su hogar?

Pero no son sólo los valores de producción los que hay que tener en cuenta y que nos han servido como abrebocas, hay un enemigo terrible que derrotar y es en este campo en donde el redactor publicitario se la juega todas: es el terrible mal de la saturación del mensaje. Para ser honestos la saturación en publicidad es el pan de cada día, pero en televisión es un enemigo monumental que sólo se puede combatir con una pluma bien afilada y blandida por un redactor sabio en los temas de la creatividad y la diferenciación.

\section{La REDACCIÓN DEL TEXTO PARA TELEVISIÓN}

Desde el punto de vista de las oportunidades que ofrecen las comunicaciones transmitidas por las ondas hertzianas, la televisión tiene una gran ventaja -y obviamente- sobre la radio, ya que utiliza en el mensaje lo mismo la acción que el sonido. La capacidad de crear un estado de ánimo o demostrar cómo se usa una marca, da a la televisión capacidad superior en comparación con todos los demás medios. Pero esto también modifica todo el concepto de redacción. En televisión, el texto debe tener muy en cuenta los aspectos visuales del anuncio, en concordancia con la forma en que los previó y especificó el director creativo. 
Las oportunidades inherentes de la televisión como medio publicitario también representan desafíos para el redactor. Es cierto que las características inherentes a la televisión hacen mucho para darle vida a las palabras del redactor. Sin embargo, las cualidades de acción de la televisión crean problemas. En primer lugar, el redactor debe recordar que las palabras no están solas. Los aspectos visuales, efectos especiales y técnicas de sonido son capaces de trasmitir un mensaje mucho mejor que la frase más pulida. En segundo, los comerciales de televisión representan para el redactor un desafío difícil en cuanto al manejo de tiempos. Es necesario que el texto se coordine con toda precisión con el video. Si la parte de video fuera sólo una ilustración continua, la tarea ya sería muy difícil. Sin embargo, los anuncios de televisión modernos tienden a recurrir a mucha edición (es decir, utilizan varias escenas diferentes) y la tarea del redactor llega a resultar una pesadilla. Este no sólo tiene que satisfacer todas las responsabilidades de incluir la información apropiada (con base en una plataforma creativa y decisiones de estrategia), sino también debe ajustar con todo cuidado la información dentro, entre y alrededor del despliegue visual que tiene lugar. Para asegurarse de que la coordinación es exacta, el redactor, el productor y el director asignado a un anuncio de televisión trabajan juntos muy de cerca, y así se cercioran de que el texto apoye y realce el elemento del video.

HAY UNA RECETA PARA CADA GUSTO. FORMAS MÁS COMUNES DE CREAR PARA TELEVISIÓN Demostración:

Gracias a la capacidad de la televisión para mostrar una marca en acción resulta un formato obvio para el anuncio por ese medio. Las marcas cuyos beneficios se derivan de alguna función tangible, pueden usar con eficacia este formato. El texto que acompaña esta clase de anuncio adorna la demostración visual. El texto de una demostración suele ser directo, pero es posible introducir con facilidad el drama en este formato, como sucede con la mayoría de comerciales para detergentes desinfectantes que atacan sin piedad a los gérmenes en la cocina, o el sistema de frenado de un automóvil, que salva a un automovilista de un accidente. La demostración con imagen y sonido permite que los televidentes aprecien toda la gama de características que una marca ofrece.

\section{Problema y solución:}

En este formato se presenta una marca que salva en una situación difícil. Este formato a menudo es un mensaje del tipo "escena de la vida", en el que un consumidor resuelve un problema con la marca anunciada. Con esta técnica se promueven con facilidad los líquidos para lavar loza, destapadores de cañerías y otros numerosos productos para el hogar. Una variación del formato básico es la promoción de una marca para la prevención de un problema. Para diversos artículos de mantenimiento de automóviles e incluso, para la industria de seguros se ha utilizado este enfoque.

\section{Música y canto:}

Muchos comerciales de televisión utilizan la música y el canto como técnica creativa. Las diversas industrias de bebidas (refrescos, cervezas y vinos) utilizan con frecuencia este formato para crear el estado de ánimo deseado frente a sus marcas. 
Además, el crecimiento de la publicidad por medio de imágenes ha generado muchos anuncios que muestran un producto en acción acompañado con música y sólo una cobertura visual del texto. Este formato de publicidad por televisión tiende a reducir la cantidad de texto, y presenta las mismas dificultades para redactarlo que el uso de

Es dificil explicarla forma en quela aspirina yotros medicamentos afectan el cuerpo humano. Las imágenes animadas dedolores decabezay de estómago simplifican el temay hacen más entendibles las demostraciones.

la música y las canciones en los textos para la radio. En nuestro país Comcel ha hecho todas sus campañas con situaciones de canto y baile, y toda la vida La Fina ha cantado su jingle hasta convertirlo en uno de los éxitos de la recordación publicitaria.

\section{Los testimoniales:}

La lectura que un vocero hace de un mensaje logra hacer un fuerte hincapié en el texto. Se Ie da prioridad sobre los elementos visuales y estos últimos lo apoyan, en lugar de que sea al contrario. Los testimonios de expertos, personas comunes y celebridades pertenecen a esta alternativa de formato. Un ejemplo del uso efectivo de un vocero experto se utilizó en la campaña de lanzamiento de Orbitel en donde María Cecilia Botero introducía la marca. Otras exitosas son las de Rama en las que se iba de calle en calle preguntándole a la gente sobre el rico sabor de la mantequilla.

\section{Diálogo:}

Al igual que en un comercial por radio, un anuncio televisado puede presentar una conversación entre dos personas o más. Los anuncios con formato de diálogo obligan al redactor a escribir un diálogo creíble y que mantenga el anuncio en movimiento. La mayor parte de los anuncios del tipo escena de la vida, donde se muestra a un esposo, una esposa o amigos usando una marca, emplea el formato de diálogo.
Viñeta:

El formato de viñeta utiliza una secuencia de anuncios relacionados como mecanismo para mantener el interés del auditorio. Las viñetas también dan a la publicidad una apariencia reconocible, que contribuye a alcanzar el conocimiento y el reconocimiento. Favorecen el manejo del tiempo, y las elipsis de este, permiten que en los pocos segundos de un comercial se cuente el paso de horas, días, meses y hasta años. Se juntan reacciones y vivencias diferentes en una sola estructura narrativa.

\section{Narración:}

Una narración es similar a una viñeta, pero no forma parte de una serie de anuncios relacionados. La narración es un formato que se distingue porque cuenta una historia, al igual que en una película, de forma, a veces lineal, combinando emociones y formas de historias dramáticas por excelencia, que contribuyen a darle una personalidad a la marca. Este formato resulta muy conveniente cuando se trata de crear campañas institucionales y de marca.

\section{Animación:}

Las caricaturas, los muñecos y las demostraciones con graficas computarizadas son técnicas de animación muy eficaces con que se comunican mensajes difíciles y que llegan a los mercados especializados, como el de los niños. Es difícil explicar la forma en que la aspirina y otros medicamentos afectan el cuerpo humano. Las imágenes animadas de dolores de cabeza y de estómago simplifican el tema y hacen más entendibles las demostraciones.

La animación por computadora requiere una gran fe por parte de los anunciantes. 
Como la mayor parte de un trabajo tan costoso lo realiza la computadora, no puede verse nada listo hasta que la animación esté ya muy adelantada y después de invertir mucho dinero.

\section{Anuncio directo:}

Este es el tipo más sencillo y común en los mensajes, tanto de radio como de televisión. Es a su vez el más fácil de redactar. Por lo general, consiste en un locutor que anuncia el mensaje de venta. Usualmente se combina con pistas musicales. Este formato se adapta prácticamente a cualquier producto y tiene un carácter informativo; por su forma simple corre el riesgo de convertirse en paisaje dentro de la radio. En televisión se hace con un anunciador frente a la cámara o utilizando una voz en off, mientras se apoya la presentación con imágenes del producto. Este formato es útil cuando se requiere de inmediatez en los mensajes a un bajo costo.

\section{TIPSDE BELLEZA PARA SUS MENSAJES EN TELEVISIÓN}

- Use la imagen.

- Permita que la parte de video del comercial realce y embellezca la parte auditiva. Dados la fortaleza y el poder de la presentación visual en la publicidad por televisión, aproveche su repercusión con el texto.

- Apoye la imagen.

- Asegúrese de que el texto no solo acompañe al video. Si todo lo que hace el texto es describir verbalmente lo que el auditorio observa, se pierde la oportunidad de comunicar información adicional o fortalecer la comunicación del video.

- Coordine el audio con el video.

- Además del uso estratégico del video, es esencial que el audio y el video no cuenten historias diferentes o descansen en diferentes tipos de convencimiento. Los propósitos duales de audio y video sólo sirven para confundir al auditorio.

- Venda el producto al mismo tiempo que divierte al auditorio.

- Los anuncios por televisión en ocasiones son más divertidos que los programas. Existe la tentación de que el redactor y el director de arte se ensimismen tanto en la emoción de una buena presentación del video que olviden que el propósito principal es entregar la comunicación que convenía.

- Sea flexible.

- Debido a las estrategias de programación de los medios, se elaboran comerciales con duraciones de 15, 20, 30 ó 60 segundos. El redactor necesita asegurarse de que la parte auditiva de un anuncio es completa y amplia dentro de tiempos variables.

- Utilice el texto con discreción.

- Si un anuncio tiene demasiadas palabras, creará una sobrecarga de información e interferirá con el aspecto visual. Cerciórese de que cada palabra tiene un trabajo que desempeñar y contribuye a la fuerza del mensaje.

- Refleje la personalidad e imagen de la marca.

- Todos los aspectos de un anuncio, el texto y los visuales, deben ser acordes con la personalidad e imagen que el anunciante desea construir o mantener para la marca.

- Construya las campañas.

- Mientras se prepara un anuncio especifico, evalué su potencial como idea sostenible. Es posible desarrollar el llamado
Mientras

se prepara un anuncio especifico, evaluésu potencial como idea sostenible. Es posible desarrollar el llamado básico del anuncio en múltiples versiones para integrar una campaña. 
básico del anuncio en múltiples versiones para integrar una campaña.

\section{TAN PODEROSA COMO DAVID FRENTEA GOLLAT LARADIO}

El día que la tierra se detuvo fue por culpa de la radio y un joven creativo: Orson Wells. Allí se mostró el potencial creativo de la radio que descansa en su capacidad para estimular un escenario en la mente del radioescucha, lo que permite al redactor crear imágenes y estados de ánimo que trascienden sobre los de cualquier otro medio.

A pesar de estas oportunidades creativas, nunca deben subestimarse las desventajas del medio. Pocos radioescuchas oyen de manera activa la programación de radio, mucho menos las interrupciones comerciales.

Algunas personas consideran que la radio tiene la responsabilidad de estimular la imaginación, mientras que otras la contemplan como un papel tapiz verbal, papel tapiz en el sentido que se emplea como relleno o acompañamiento discreto a la lectura, la conducción de vehículos, los quehaceres domésticos o los deberes escolares. Si no existiera, la persona común la echaría de menos en muchos contextos. Por otra parte, la misma persona tendría muchos problemas para recordar los anuncios radiofónicos difundidos durante la cena de la noche anterior.

El punto de vista más razonable en cuanto a la redacción de textos para radio consiste en equilibrar tanto el optimismo de la perspectiva de poner la mente a volar, como el pesimismo del punto de vista del papel tapiz verbal. Un redactor de textos para radio debe reconocer el carácter singular del medio y explotar las oportunidades que ofrece. En primer lugar, la radio agrega la dimensión del sonido a la tarea de redacción, y el sonido es capaz de convertirse en una herramienta primordial en la creación de textos. En segundo, la radio evoca imágenes en la mente del receptor que van más allá de la desnudez de la información que en calidad se proporciona. En consecuencia, la redacción debe luchar por estimular la imaginación de cada radioescucha.

Para redactar textos para radio las formas son las mismas utilizadas para la redacción de textos impresos. Después de revisar los componentes del plan estratégico se hacen guiones que guarden todo el interés posible y conserven la estrategia.

\section{FORMATOS UTILIZADOS PARA HACER RADIO}

Cuñas.

Grabaciones sonoras compuestas de palabras, música o ambas conjuntamente de una duración de 15 a 60 segundos generalmente.

\section{Flash.}

Cuñas cortas de un máximo de 10 segundos.

\section{Menciones.}

Textos publicitarios emitidos en directo con o sin fondo musical. Muy usuales en los eventos deportivos.

Comunicados.

Textos informativos y publicitarios.

\section{Prescripciones.}

Menciones a modo de recomendación sutil dichas por el locutor-comunicador del programa. 
Promos.

Cuñas o textos que promocionan un espacio patrocinado por el anunciante con presencia publicitaria del mismo.

Patrocinios.

Patrocinio de un programa o espacio de interés para la audiencia.

Se inicia con un flash como careta de entrada, contenido programático. Y una cuña de salida del patrocinador.

\section{Microprogramas.}

Al igual que el anterior, pero con una duración no superior a cinco. En algunos casos el contenido puede llegar a seguir una línea publicitaria del producto.

\section{Infomerciales.}

Programas, micros o retransmisiones en directo realizados y producidos por la firma publicitaria que lo patrocina.

\section{Concursos.}

Generalmente microprogramas donde el contenido, premios y participación de la audiencia gira en torno al patrocinador o anunciante.

\section{Unidades móviles.}

Microprogramas o patrocinios publicitarios que se realizan desde la calle retransmitiendo o grabando un acontecimiento de promoción o de ventas en distribuidores, exposiciones, etc.

\section{Publirreportajes.}

Son publirreportajes de interés para la audiencia en forma de micro comunicados, realizados por los equipos de la emisora.
Entrevistas.

Preguntas y respuestas con o sin intervención de la audiencia con un representante o especialista facilitado por la firma anunciante, a modo de microespacio.

\section{Acciones especiales.}

Coordinación de varios medios nacionales o locales, o ambos a la vez, para apoyar acciones de mercadeo promocional y de ventas, combinando prescripciones, unidades móviles, concursos, cuñas, etc.

\section{LA MÚSICA PUEDE HACER TODO MÁS INOLVIDABLE EN LA RADIO.}

Por su capacidad auditiva una de las formas más celebres es la música, a la que se recurre con frecuencia. Esto consiste en la composición de una canción o un jingle con la intención de comunicarse de una forma memorable y que atraiga la atención. Por lo general, las canciones y los jingles se componen de manera especifica para amoldarse al texto de una marca. En ocasiones, es posible utilizar una canción ya conocida, y la letra se ajusta al metro y ritmo de la canción. Esto es cierto en especial si se usa la música para captar la atención de un segmento específico. Los anunciantes, mediante una licencia que se les otorga, pueden hacer uso de melodías populares con determinados segmentos objetivos.

El canto y la música hacen mucho para atraer la atención de los radioescuchas y fortalecer el recuerdo. El canto también es capaz de crear un determinado estado de ánimo e imagen con los que se asocia el producto. Las partituras modernas crearán un estado de ánimo contemporáneo, mientras que música y letra sensuales crean un estado de ánimo por completo diferente. 
Existen ciertos riesgos en el uso del canto o jingle. Pocos redactores son compositores capacitados. La amenaza siempre presente es que una partitura musical de un jingle o tonadilla parezca a los radioescuchas tonta y no profesional. Para evitar este problema, a menudo se recurre a compositores expertos. Además, hace falta una gran habilidad
Muchos diálogos se escriben con un ingrediente extra de humor, y bien interpretados le dan una carga dramática a las cuñas, haciéndolas más relevantes que el anuncio típico. para asegurarse de que la información del texto domina al acompañamiento musical. La fuerza musical quizá logre con facilidad el convencimiento y los propósitos de venta de un anuncio.

Otro uso de la música en los comerciales radiofónicos consiste en comenzar el anuncio con una introducción musical y/o hacer que la música sirva de fondo mientras se lee el texto. Aquí, la función de la música por lo general radica en atraer la atención.

\section{EN LA RADIO NACIERON LAS NOVELAS.}

EL DIÁLOOGO

La técnica del diálogo es útil cuando se tiene un espacio de tiempo que permita un desarrollo del diálogo fluido, sin que las situaciones se vean forzadas y que logre envolver a las personas de forma llamativa. Muchos diálogos se escriben con un ingrediente extra de humor, y bien interpretados le dan una carga dramática a las cuñas, haciéndolas más relevantes que el anuncio típico.

\section{TIPSDE BELLEZA PARA SUS CUÑAS DE RADIO}

- Exprese la gran idea con toda claridad.

- Concéntrese en el punto principal de venta. La radio es un excelente medio para dar a conocer la marca, pero no para hacer listas largas sobre los atributos del producto, ni mucho menos para exponer argumentos complicados.
- Mencione el nombre del anunciante al inicio y con frecuencia.

- Si el nombre del producto o de la compañía es complicado, tal vez convenga deletrearlo. Disponga de suficiente tiempo para preparar la escena y comunicar el mensaje. Un comercial de 30 segundos que nadie recuerda después es un desperdicio de dinero. Luche por conseguir cuñas de 60 segundos.

- Utilice efectos sonoros conocidos.

- El tintineo del hielo en un vaso, el trinar de los pájaros o el chirrido de una puerta que se cierra pueden crear una imagen visual. También la música da buenos resultados.

- Pinte imágenes con palabras.

- Use el lenguaje descriptivo para hacer más memorable el anuncio.

- Sáquele el máximo partido a cada palabra.

- Use la voz activa y más verbos que adjetivos. Utilice un tono coloquial. Prefiera las palabras fácilmente pronunciables y las oraciones cortas.

- Sea extravagante.

- Los mejores comerciales cómicos comienzan con una observación totalmente absurda la cual es fluida y no reforzada. Pero recuerde: si no es un talento en anuncios humorísticos, mejor escriba un texto dramático.

- Recuerde que la radio es un medio local.

- Adapte sus comerciales al lenguaje del auditorio y a la hora del día en que se transmiten.

- La producción es un factor decisivo.

- Aun los mejores guiones parecen aburridos en el papel. Cobran vida con la actuación, la manipulación de la voz y los 
efectos sonoros. No deje que los locutores hablen como salidos de ultratumba.

- Destaque la razón de la venta.

- Haga que sus historias giren en torno a los argumentos de venta, consignados en la estrategia. No los deje de lado, ni los sacrifique por la historia. Ponga la historia al servicio del mensaje.

\section{GLOSARIO}

Lema: Texto corto o frase de sentido completo que resume en su esencia el valor estratégico de la marca.

Viñeta: Cuadro de composición visual que contiene un momento de acción para el lenguaje de la televisión o de los comics.

Voz off: Comando utilizado para denotar a la persona que habla, pero de la cual no vemos su imagen.

Comercial: Voz utilizada para nombrar la pieza publicitaria que se crea para ser pautada en televisión y que tiene un interés económico para el anunciante.
Redactor creativo (Copywriter, copy). Es quien asume la función textual de la publicidad en las agencias.

\section{BIBLIOGRAFÍA}

- ARENS, William (2002). Publicidad, México: Mc Graw Hill.

- BERDINGER, Bruce (1993). The Copy Workshop. Chicago: editado por él mismo.

- FigueroA B., Romeo (1999). Cómo hacer publicidad. México: Pearson Education.

- FELTON, George (1995). Advertising Concept and Copy. New Yersey: Prentice Hall.

- JEWLER, Jerome (1994). Creative Strategy in Advertising, Estados Unidos: Thompson Publishing Company.

- MOLINE, Marcal (2002). La fuerza de la publicidad. Madrid: Mc Graw Hill. 